\title{
UM OLHAR SOBRE ASPECTOS DE FRAÇÃO PRESENTES NA PRIMEIRA PROVA DO SISTEMA DE AVALIAÇÃO DO ESTADO DO TOCANTINS
}

\author{
A LOOK AT ASPECTS OF FRACTION PRESENT IN THE FIRST TEST OF THE \\ EVALUATION SYSTEM OF THE STATE OF TOCANTINS
}

DOI: http://dx.doi.org/10.23926/RPD.2526-2149.2019.v4.n1.p114-133.id382

\author{
Severino Roberto de \\ Lima \\ Mestrando em Educação pela \\ Universidade Federal do \\ Tocantins (UFT) \\ Professor da Educação \\ Básica na Rede Estadual do \\ Tocantins (SEDUC-TO) \\ robertolm44@gmail.com
}

\section{Ritianne de Fátima \\ Silva de Oliveira}

Mestranda em Educação pela

Universidade Federal do

Tocantins (UFT)

Professora da Educação

Básica na Rede Municipal de

Canaã dos Carajás (SEMEC-

$\mathrm{CC})$

ritianne19@hotmail.com

\section{Ademir Brandão \\ Costa}

Mestrando em Educação pela

Universidade Federal do

Tocantins (UFT)

Professor da Educação

Básica na Rede Estadual do

Pará (SEDUC-PA)

ademirbrandao@gmail.com

\section{Idemar Vizolli}

Doutor em Educação (PPGEUFPR)

Professor na Universidade

Federal do Tocantins (UFT)

idemar@uft.edu.br
Resumo: O conteúdo de fração está presente no currículo escolar desde os Anos Iniciais do Ensino Fundamental; integra avaliações de larga escala de sistemas de avaliação da União, Estados e Municípios; e tem sido objeto de pesquisas em programas stricto sensu. Este estudo integra uma pesquisa mais ampla em desenvolvimento por professores e estudantes dos Cursos de Mestrado Acadêmico e Profissional da Universidade Federal do Tocantins e tem como objetivo analisar os aspectos de fração que se fazem presentes em questões da prova do Sistema de Avaliação do Estado do Tocantins (SAETO), aplicada aos estudantes do $9^{\circ}$ ano do Ensino Fundamental e do $3^{\circ}$ ano do Ensino Médio, no ano de 2011. Trata-se de uma pesquisa de natureza qualitativa, em que se fez uso de consulta bibliográfica e documental. As análises inspiram-se na teoria dos registros de representação semiótica, significados de fração e características das quantidades. Foram analisadas 06 questões (cinco do $9^{\circ}$ ano e uma do $3^{\circ}$ ano). Os resultados indicam que se devem considerar os aspectos supramencionados por ocasião do processo de ensino e aprendizagem, de modo que os estudantes compreendam o conceito de fração.

Palavras-chave: Educação; Avaliação em larga escala; Sistema de Avaliação do Estado do Tocantins; Fração.

\begin{abstract}
The fraction content is present in the school curriculum since the Early Years of Elementary School; it integrates large-scale assessments of Union, State and municipal evaluation systems; and it has been the subject of research in stricto sensu programs. This study integrates a broader research in development by professors and students of the Academic and Professional Master Programs of the Federal University of Tocantins and it aims to analyze the aspects of fraction that are present in questions of the proof of the System of Evaluation of the State of Tocantins (SAETO), applied to students of the 9th year of Primary Education and 3rd year of High School, in 2011. This is a qualitative research, in which bibliographical and documentary consultation was used. The analyzes are inspired by the theory of semiotic representation registers, fraction meanings and quantity characteristics. Six questions were analyzed (five from the 9 th year and one from the 3rd year). The results indicate that one should consider the aforementioned aspects during the teaching and learning process, so that students understand the concept of fraction. Keywords: Education; Large scale evaluation; Evaluation System of the State of Tocantins; Fraction.
\end{abstract}




\title{
1 INDICATIVOS DE PESQUISAS EM RELAÇÃO AO CONTEÚDO DE FRAÇÃO
}

$\mathrm{Na}$ perspectiva de esclarecer a problemática em que se insere o processo de ensino e aprendizagem de fração, perpassamos por pesquisas que versam sobre essa temática e apresentamos os objetivos e a metodologia do presente estudo.

Ao recorrer à História da Matemática, verificamos que o povo egípcio desenvolveu a escrita dos números e formulou o conceito de fração a partir da demarcação de terras com vistas à cobrança de impostos. Para aferir as medidas dos terrenos, os agrimensores distendiam uma corda sobre o contorno da área a ser medida, assim passavam a saber a quantidade de côvados (medida do cúbito indicando a medida entre os nós da corda) daquele espaço. Uma vez que nem sempre o terreno comportava medidas inteiras do cúbito, surgiu a necessidade de se utilizar parte dele (subunidades), ou seja, fracionar a unidade. Para além de situações da vida prática, os hindus utilizavam a fração na Matemática. Embora o conceito de fração seja bastante antigo, ainda gera a necessidade de novos estudos, especialmente em relação ao processo de ensino e aprendizagem. A contemporaneidade é marcada pelas tecnologias e pelo desenvolvimento das ciências e, entre elas, a Matemática. No contexto educacional e da pesquisa, a compreensão do conceito de fração se reveste de condição fundante para a vida contemporânea.

Os estudos de Bertoni (2004) indicam que o conteúdo de fração apresenta uma série de problemas de aprendizagem nos Anos Iniciais do Ensino Fundamental e que as avaliações nacionais expressam baixo índice de acertos em questões que tratam desse conceito.

\begin{abstract}
A matriz de descritores da $4^{a}$ série do SAEB - Sistema Nacional de Avaliação da Educação Básica, MEC/INEP - também não inclui essas operações. Por outro lado, não se nota, de modo geral, nos livros e nas propostas curriculares de $5^{\mathrm{a}}$ a $8^{\mathrm{a}}$ série, mudanças no sentido de uma introdução mais cuidadosa às frações e às operações entre elas, visando suprir essa lacuna deixada nas séries iniciais. Isso nos leva à constatação de que o espaço para a aprendizagem desses números nas séries iniciais foi diminuído e não houve ganho de espaço nas séries finais (BERTONI, 2004, p. 1).
\end{abstract}

Ao analisar o desempenho de estudantes de $5^{\mathrm{a}}$ e $6^{\mathrm{a}}$ séries em relação aos diferentes significados de frações, Merlini (2005) percebeu que somente 35\% deles obteve sucesso nas respostas às questões. Nunes e Bryant (1997) sugerem que as dificuldades dos estudantes residem no fato de eles não distinguirem as características particulares dos conjuntos numéricos. Notou-se que eles transferem as propriedades do conjunto dos Números Naturais para o conjunto dos Números Racionais, incluindo-se as frações. Além disso, há estudantes concluindo a Educação Básica sem necessariamente ter superado dificuldades em relação à compreensão do conceito de fração. 
Para Bertoni (2004), os estudantes devem compreender que os números racionais se desdobram nas representações decimal (bastante usual no meio social e aparecem com bastante frequência em quantias monetárias e medidas) e fracionária (mais usuais em particionamentos da unidade e bastante presente quando se trata de razões, escalas, porcentagens e probabilidade). Comumente referimo-nos à metade de uma laranja, por exemplo, e escrevemos $1 / 2$ e raras vezes representamos por 0,5 .

\begin{abstract}
Ainda que facetas de um mesmo número, as duas representações são, geralmente, tratadas de modo estanque, como se dissessem respeito a números diferentes números decimais e frações. Isto é, confundem-se o número e suas representações. [...] Tradicionalmente, três modelos têm sido adotados no ensino e aprendizagem de frações: o modelo discreto; as figuras geométricas, principalmente quadrados, retângulos e círculos; e a representação na reta numérica (BERTONI, 2004, p. 1-2).
\end{abstract}

A pesquisa de Vizolli (2006) indica que, ao solucionar situações que envolvem fração, estudantes da Educação de Jovens e Adultos (EJA) ancoram seus raciocínios em situações que lhes são familiares, como metade e quarta parte, por exemplo. Trata-se de estratégias interessantes do ponto de vista da aprendizagem, mas que exigem da parte de quem ensina a mobilização de conhecimentos produzidos, na maioria das vezes, por meio da pesquisa.

Ao observarmos o modo como as situações de fração são trabalhadas em sala de aula e, muitas vezes, apresentadas pelos livros didáticos, percebe-se que há uma diferença em relação ao modo como são cobradas nas avaliações de desempenho.

O estudo que ora realizamos insere-se no escopo das pesquisas em desenvolvimento por um grupo de professores e estudantes vinculados aos Programas de Mestrado Acadêmico e Profissional em Educação da Universidade Federal do Tocantins. Essas pesquisas versam sobre o processo de ensino e aprendizagem de fração e têm como objetivo geral analisar os aspectos de fração presentes em questões da prova do Sistema de Avaliação do Estado do Tocantins, aplicada aos estudantes do $9^{\circ}$ ano do Ensino Fundamental e do $3^{\circ}$ ano do Ensino Médio, em 2011. Para tanto, estabelecemos como objetivos específicos entender a dinâmica do Sistema de Avaliação do Estado do Tocantins (SAETO); identificar na literatura os registros de representação semiótica fundamentais à compreensão do conceito de fração, os diferentes significados que a fração comporta, assim como a natureza das quantidades; e verificar que aspectos da fração se fazem presentes nas questões da prova do SAETO de 2011.

Trata-se de uma pesquisa de natureza qualitativa, em que se fez uso de consulta bibliográfica e documental. De acordo com Gil (2002), a pesquisa bibliográfica tem como base material já elaborado e constituído principalmente por teses, dissertações, livros e artigos científicos. Já as pesquisas documentais ancoram-se na análise de documentos, como leis, 
decretos, normativas, pareceres, atas, diretrizes, dentre outros. A pesquisa bibliográfica proporcionou uma aproximação com o objeto a ser estudado, ao mesmo tempo em que possibilitou acurar os aspectos metodológicos.

O presente estudo tem assento nas questões que envolvem fração, presentes na prova do SAETO de 2011 de $9^{\circ}$ ano do Ensino Fundamental e de $3^{\circ}$ ano do Ensino Médio, considerandose as categorias relativas aos registros de representação semiótica, significados de fração, características das quantidades. A escolha de "fração" se deve ao fato de que ela integra os conteúdos curriculares de matemática desde os anos iniciais; não é um conteúdo trivial para os estudantes; figura nas avaliações em larga escala; e encontra-se na centralidade do projeto de pesquisa mais amplo. Já a opção de analisar as questões do SAETO/2011, se deve ao fato de entendermos que os estudantes do $9^{\circ}$ ano do Ensino Fundamental e do $3^{\circ}$ ano do Ensino Médio, em tese, compreendem o conceito de fração. Foram analisadas seis questões (cinco do $9^{\circ}$ ano do Ensino Fundamental e uma do $3^{\circ}$ ano do Ensino Médio).

\section{DaS AVAliaÇões EM laRga ESCALA AO SAETO}

Há algum tempo em congressos, palestras e seminários nacionais e internacionais, discutem-se questões relacionadas à avaliação da aprendizagem, avaliação institucional, avaliação em sala de aula e avaliação em larga escala, além dos trabalhos apresentados e das pesquisas realizadas no âmbito da avaliação educacional. Estudos realizados por Gatti (2009) demonstram que a avaliação educacional é um campo de estudos com teorias, processos e métodos específicos, e também um campo abrangente que comporta subáreas, com características próprias, como é o caso das avaliações realizadas por sistemas educacionais, da avaliação de desempenho escolar em nível de sala de aula, da avaliação institucional, da avaliação de programas e da autoavaliação. Ela comporta também diferentes abordagens teóricas (sistêmica, iluminativa ou compreensiva, avaliação participativa, dentre outras).

No contexto histórico brasileiro, com os vários problemas decorrentes das mazelas sociais do processo de colonização e do desordenado crescimento demográfico, acirrado na segunda metade do século passado, os educadores passaram a enfrentar de forma mais contundente os altos índices de analfabetismo, adensando-se com a distorção idade-série. Em decorrência dessa problemática, desnuda-se a precariedade do sistema educacional brasileiro e, como forma de enfrentamento, estabelece-se a constituição de unidades de ensino para acolher adolescentes, jovens e adultos sem escolarização ou com baixos índices de escolaridade. 
De acordo com Bonamino (2002) e Freitas (2004), avaliações de sistemas educacionais tiveram seu início com a proposição do Sistema Nacional de Avaliação do Ensino Público de $1^{\circ}$ grau (SAEP). Segundo Gatti (2009), no final dos anos de 1980, ocorreu uma série de discussões relacionadas aos problemas nos sistemas educacionais, e as pesquisas trouxeram à baila os altos índices de evasão e repetência, sobretudo na Educação Básica brasileira, mas ainda não se contava com dados sobre fatores associados a tais problemas. As avaliações realizadas entre 1988 e 1991 revelaram baixos índices no rendimento e defasagem escolar dos estudantes. Os impactos gerados por essas avaliações motivaram o Ministério da Educação e Secretarias de Educação a implantar uma avaliação em larga escala: o Sistema de Avaliação da Educação Básica (SAEB). Posteriormente, em 1998, o governo federal implantou o Exame Nacional do Ensino Médio (ENEM); em 2002, foi instituído o Exame Nacional de Certificação de Competências de Jovens e Adultos (ENCCEJA).

Em 2005, o SAEB passou a ser constituído pela Avaliação Nacional da Educação Básica (ANEB) e a Avaliação Nacional do Rendimento Escolar (ANRESC), conhecida nos dias atuais como Prova Brasil. Tratam-se de avaliações censitárias, cujos resultados são disponibilizados para cada estado da federação, por município e unidade escolar, com possibilidades múltiplas de análise e delineamento de novas ações pedagógicas, a partir da qualidade do ensino que se materializa pelas aprendizagens dos estudantes.

\begin{abstract}
Duas recentes ações do Ministério da Educação alteram a composição do Saeb. A primeira é a que inclui a Avaliação Nacional da Alfabetização - ANA, no âmbito do que prevê o Pacto Nacional pela Alfabetização na Idade Certa-PNAIC, que se caracteriza por provas de Leitura e Escrita e prova de Matemática a estudantes matriculados no $3^{\circ}$ ano do ensino fundamental, em escolas públicas, localizadas nas zonas urbana e rural, que estejam organizadas no regime de nove anos, sendo censitária para as turmas regulares e amostral para as turmas multisseriadas. A segunda, aplicação, em caráter experimental, para validação das matrizes e escalas, de testes de Ciências definidos nas Matrizes de Referência do SAEB para o $9^{\circ}$ ano do ensino fundamental e para o $3^{\circ}$ ano do ensino médio (SOUSA, 2014, p. 409-410).
\end{abstract}

Além de realizar um diagnóstico do sistema educacional brasileiro e de alguns fatores que possam interferir no desempenho dos estudantes, fornecendo um indicativo sobre a qualidade do ensino que é ofertado, o SAEB também oferece dados e indicadores que possibilitam compreender melhor os fatores que influenciam o desempenho dos estudantes; subsidia o monitoramento das políticas públicas educacionais nas esferas federal, estaduais e municipais; e contribui para a melhoria da qualidade, equidade e eficiência do ensino.

Atualmente o SAEB é composto por três avaliações externas em larga escala: a ANEB, que contempla amostra de estudantes das redes públicas e privadas do país, matriculados no $5^{\circ}$ ano e no $9^{\circ}$ ano do Ensino Fundamental e no $3^{\circ}$ ano do Ensino Médio, tendo como principal 
objetivo avaliar a qualidade, a equidade e a eficiência da educação brasileira; a ANRESC (Prova Brasil), uma avaliação censitária que envolve estudantes do $5^{\circ}$ ano e do $9^{\circ}$ ano do Ensino Fundamental das escolas públicas e tem como objetivo avaliar a qualidade do ensino; e a ANA, a qual se constitui de uma avaliação censitária envolvendo estudantes do $3^{\circ}$ ano do Ensino Fundamental das escolas públicas e tem o objetivo principal de avaliar os níveis de alfabetização e letramento em Língua Portuguesa, alfabetização Matemática e condições de oferta do Ciclo de Alfabetização das redes públicas.

Como parte integrante do Plano de Desenvolvimento da Educação (PDE), o Instituto Nacional de Estudos e Pesquisas (INEP) criou, em 2007, o Índice de Desenvolvimento da Educação Básica (IDEB), o qual se constitui num indicador de qualidade que combina informações relativas ao desempenho de estudantes em exames como a Prova Brasil ou SAEB e sintetiza informações de desempenho com informações sobre o rendimento escolar (taxa média de aprovação dos estudantes na etapa de ensino).

Gatti (2009) compreende que fatores internos e externos interpuseram-se e as contradições implicadas nesses procedimentos tomaram corpo.

De um lado, uma ênfase muito forte que acaba sendo dada aos melhores e aos piores desempenhos, a mídia valorizando apenas a média das notas obtidas e não outros resultados até mais importantes. De outro, observou-se a pequena utilização dos dados por parte das redes, seja por processos inadequados de disseminação e de dar acesso e visibilidade aos dados, seja por dificuldades nas redes de lidar, analisar, interpretar esses dados pedagogicamente (GATTI, 2009, p. 15).

De acordo com a autora, o grande desafio consiste na apropriação dos resultados por parte das escolas e da comunidade como um todo, bem como na utilização dos dados e informações para orientar as atividades de ensino.

De acordo com Sousa (2013), ao que se parece, a criação da Prova Brasil e a definição de um índice de qualidade pelo Ministério da Educação, mesmo com limitações em relação aos indicadores considerados para aferir a qualidade do ensino, os resultados da proficiência dos alunos em provas e fluxo exerceram um poder indutor de iniciativas estaduais de implantação de sistemas próprios de avaliação.

O que se evidencia é uma tendência de governos estaduais organizarem seus sistemas
de avaliação, em moldes semelhantes ao delineado pelo Ministério da Educação,
assumindo como principal indicador de qualidade das redes e escolas a medida da
proficiência dos alunos, obtida por instrumentos de testagem, apoiados na adesão à
ideia da necessidade da avaliação para qualificar a gestão da educação (SOUSA, 2013,
p. 67).

Com a intensificação crescente das avaliações externas no âmbito das gestões estaduais e com a utilização e visibilidade dos resultados alcançados pelas escolas como 
mecanismo de monitoramento e delineamento das ações pedagógicas, a Secretaria da Educação, Juventude e Esportes do Tocantins, em 2011, implantou o Sistema de Avaliação da Educação do Estado do Tocantins (SALTO), hoje Sistema de Avaliação do Estado do Tocantins (SAETO), para verificar a proficiência dos estudantes da rede estadual em Língua Portuguesa e Matemática, no $5^{\circ}$ e $9^{\circ}$ ano do Ensino Fundamental e no $3^{\circ}$ ano do Ensino Médio. Essa avaliação é realizada bianualmente.

Cabe registrar que o SAETO integra o Plano Estadual de Educação do Tocantins (PEE/TO, 2015-2025), Lei 2.977, de 08 de julho de 2015, a qual preconiza:

Art. 10. O Sistema Estadual de Avaliação da Educação Básica do Tocantins - SAETO, coordenado pela Secretaria da Educação, em colaboração com os Municípios, constitui fonte de informação para a avaliação da qualidade da educação básica e para a orientação das políticas públicas deste nível de ensino.

$\S 1^{\circ} \mathrm{O}$ sistema de avaliação a que se refere o caput deste artigo produz, no máximo, a cada dois anos:

I - indicadores de rendimento escolar, referentes ao desempenho dos alunos, apurado em exames nacionais e estaduais de avaliação, com participação de, pelo menos, $80 \%$ dos alunos de cada ano escolar, periodicamente, avaliado em cada escola, e aos dados pertinentes apurados pelo Censo Escolar da educação básica;

II - indicadores de avaliação institucional, relativos a características como o perfil do alunado e do corpo de profissionais da educação, as relações entre dimensão do corpo docente, do corpo técnico e do corpo discente, a infraestrutura das escolas, os recursos pedagógicos disponíveis e os processos da gestão.

$\S 2^{\circ}$ A elaboração e a divulgação de índices para avaliação da qualidade, como o Índice de Desenvolvimento da Educação Básica - IDEB, que agreguem os indicadores mencionados no inciso I do §1o deste artigo não elidem a obrigatoriedade de divulgação, em separado, de cada um deles.

$\S 3^{\circ}$ Os indicadores mencionados no $\S 10$ deste artigo são estimados por etapa, estabelecimento de ensino e rede escolar, em âmbito estadual, sendo amplamente divulgados, ressalvadas publicação de resultados individuais e indicadores por turma, que fica admitida, exclusivamente, para a comunidade do respectivo estabelecimento e para a Secretaria da Educação.

$\S 4^{\circ}$ Cabem ao SAETO, coordenado pela Secretaria da Educação, a elaboração e o cálculo dos resultados e dos indicadores referidos no $\$ 1^{\circ}$ deste artigo (TOCANTINS, 2015, p. 4-5).

Assim, a Secretaria da Educação, Juventude e Esportes do Tocantins, visando o fortalecimento da gestão escolar e das práticas pedagógicas do professor em sala de aula e, com base no Referencial Curricular do Ensino Fundamental, Proposta Curricular do Ensino Médio e Matriz de Referência da Prova Brasil, que norteiam o SAETO, apresenta guias pedagógicos destinados aos professores. Esses guias são elaborados a partir de itens comentados e tem como objetivo propor elementos que possibilitem reflexões, na perspectiva de subsidiar o trabalho pedagógico do professor em sala de aula. Os itens considerados para elaborar as provas do SAETO têm assento nos eixos estruturantes indicados nos Parâmetros Curriculares Nacionais 
(PCN), no caso da Matemática: Espaço e Forma; Grandezas e Medidas; Números e Operações/Álgebra e Funções; Tratamento da Informação.

\section{ASPECTOS A SEREM CONSIDERADOS NAS ANÁLISES}

Para analisar as questões de fração presentes na avaliação do SAETO/2011, adotamos como categorias de análise os registros de representação semiótica de Duval (1993; 1995; 2003); os significados de fração, propostos por Nunes et al (2003); e as características das quantidades de que também tratam Nunes et al (2005).

\subsection{REgisTROS DE REPRESENTAÇÃo SEMIÓTICA NECESSÁRIOS À COMPREENSÃo DE FRAÇÃO}

As representações permitem aos sujeitos elucidar as ideias e/ou imagens de um determinado objeto, o que reverbera em uma possibilidade metodológica para que o professor auxilie os estudantes a aprimorar suas ideias, expressões, concepções ou os registros de um dado objeto matemático, chegando às representações semióticas. Essas, por sua vez, são formadas por um conjunto de signos pertencentes a um sistema de representação, que apresentam características próprias de significado e funcionamento. E, ainda, as representações semióticas comportam um sistema particular de signos, de linguagem, de escrita algébrica ou gráficos cartesianos, e podem ser convertidas em representações equivalentes, dentro de outro sistema semiótico, embora possam apresentar significados diferentes para quem as utiliza (DUVAL, 1993; 1995; 2003).

Segundo Duval (1993), os diversos registros de representação semiótica são intrínsecos à função cognitiva do pensamento, o que torna impossível sua separação, isso porque não há noésis (apreensão conceitual do objeto) sem semiósis (produção de uma representação). Ele destaca três perspectivas para o termo "representação": as representações mentais, internas ou computacionais e semióticas.

As representações mentais permitem uma visão de objeto na ausência de todo significante; são comumente chamadas de imagens mentais, mas também podem estar ligadas aos conceitos, ideias, noções e crenças; e estão relacionadas à objetivação ou tomada de consciência, que pode ser entendido como comunicação para outrem; do ponto de vista cognitivo elas são conscientes e essenciais para fins de conceitualização.

As representações internas ou computacionais estão relacionadas ao tratamento de informações de forma mecânica por um sistema; portanto não são representações conscientes do sujeito, este apenas o executa. 
Já as representações semióticas estão relacionadas a um sistema de signos, linguagem, gráficos, que podem ser transformados em outros sistemas, também semióticos, de representação equivalente, com significações diferentes. Elas pressupõem as funções cognitivas de objetivação, tratamento e conversão. "O desenvolvimento das representações mentais efetua-se como uma interiorização das representações semióticas da mesma maneira que as imagens mentais são uma interiorização das percepções" (DUVAL, 2009, p. 17).

A objetivação consiste na comunicação de uma ideia para outrem; o tratamento ocorre dentro de um mesmo sistema semiótico, implica na forma ou meio utilizado para internalizar o pensamento; e a conversão consiste na passagem do registro de um sistema semiótico para outro também semiótico. A função de conversão implica na mudança no sistema de registro de representação semiótica de partida, que, a depender do objeto a ser representado, pode não ser trivial para muitos estudantes, exatamente porque há a necessidade de diferenciar representante e representado. Para Duval (1993; 2003), a utilização de vários registros de representação (várias escrituras para os números, linguagem natural, figuras geométricas, gráficos cartesianos, operações matemáticas, entre outras) é fundamental para a aprendizagem de matemática. $\mathrm{O}$ autor assevera que é importante não confundir funções, por exemplo, com sua representação gráfica. No caso em estudo, não se deve confundir a fração com suas representações gráficas, decimais, fracionária, percentual.

No caso dos números racionais, Vizolli (2006) argumenta que os estudantes conseguem dar um tratamento com representações decimais e algumas vezes representações fracionárias; no entanto, não percebem que 0,1 e $1 / 10$ são representações de um mesmo número ou objeto matemático (número racional).

De acordo com Santana (2012), a fração pode contemplar os registros de representação semiótica: simbólico (que compreende os numéricos ou algébricos); figural, no qual se devem levar em consideração as quantidades contínuas e discretas; linguagem natural, por exemplo, "dois terços"; registros concretos (representando objetos), conforme disposto na Figura 1, a seguir. Pelos estudos de Vizolli (2001; 2006), a porcentagem também pode ser vista como uma fração, cujo denominador é 100. 
Figura 1 - Registro de representação semiótica sobre fração

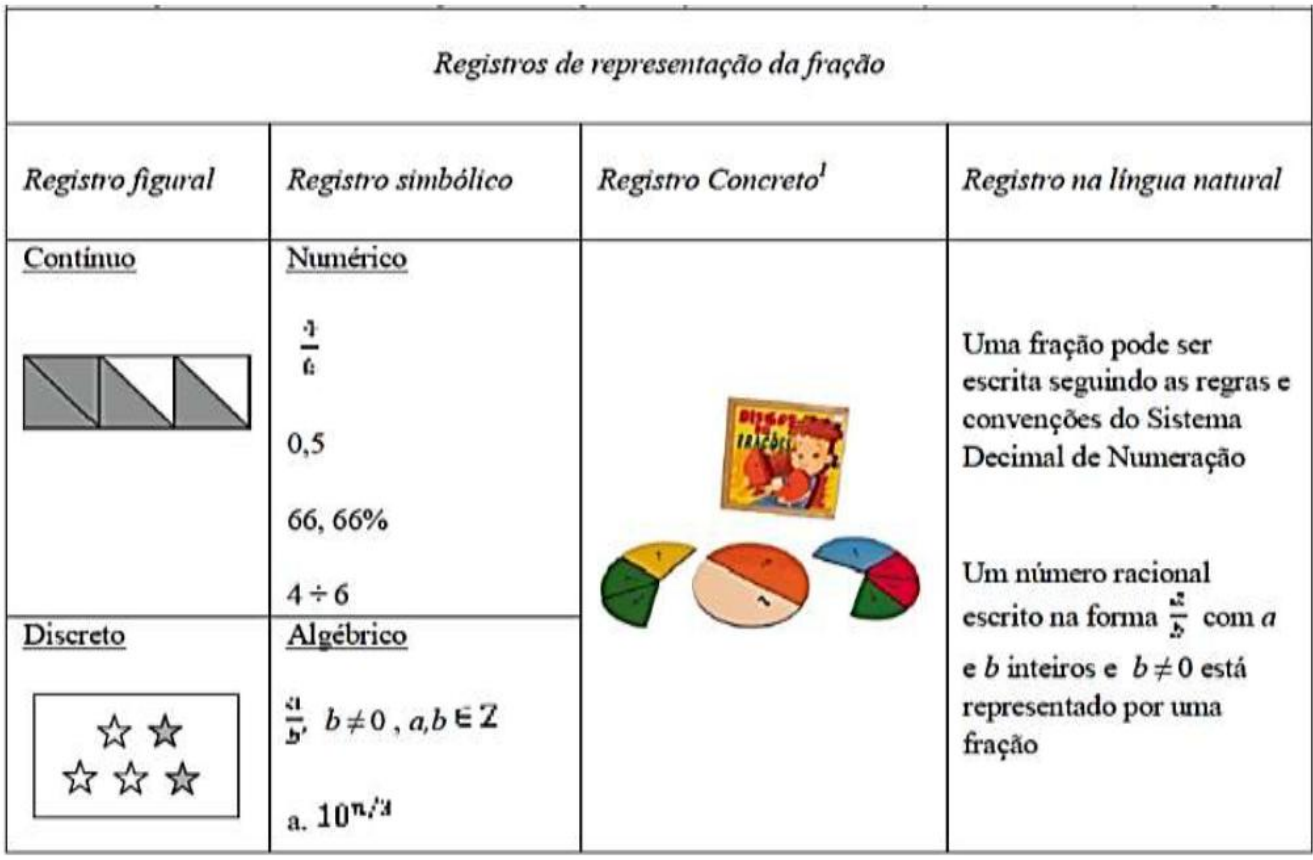

Fonte: Santana (2012, p. 65-66).

Conforme aponta Santana (2012), os registros fracionários são os mais utilizados dentre os numéricos, o que pode ser justificado pelo fato de serem os mais usados nas aulas sobre esse conteúdo. Dessa maneira, ao passar de um registro para outro, os fracassos e bloqueios aumentam consideravelmente porque os estudantes não aprenderam que para um mesmo objeto matemático existem diferentes representações. Isso significa que há um "enclausuramento" provocado pela utilização constante do mesmo registro, que impede o reconhecimento de outro objeto matemático em representações diferentes. Tal fato denota ainda a confusão entre representante e representado, ou seja, entre a fração e seus registros de representação semiótica (SANTANA et al, 2013, p. 11).

No caso das frações, podemos representá-las de formas distintas, mantendo-se o conteúdo representado, ou em outros termos, muda-se a forma de representar, mas não o objeto representado: Em língua natural $=$ meio ou metade; Fracionário $=1 / 2 ;$ Decimal $=0,5$; Figural $=\nabla ;$ Percentual $=50 \%$.

Corroborando com o que assevera Duval (1993; 1995; 2003), os estudos de Bertoni (2002) indicam que a compreensão do conceito de fração necessita da utilização de um conjunto de representações simbólicas, linguísticas, gráficas e gestuais, capazes de representar situações e procedimentos intimamente ligados ao conceito. $\mathrm{O}$ exposto denota que a formação do conceito pelo estudante requer uma metodologia de ensino articulada às situações cotidianas, cujo 
processo de ensino perpassa pela proposição de respostas de modo informal, mentalmente ou por meio de falas.

\subsection{A FRAÇÃO E SEUS SIGNIFICADOS}

Quando nos referimos à fração, logo nos vem à mente parte de algo ou alguma coisa, o que denota, dentre outras, as ideias de parcela, pedaço, quebra, divisão, dividir em partes iguais e está na matriz das palavras "fracionamento", "infração", "fracionário". Em matemática, ela se insere no campo dos números racionais. Para Kieren e Pirie (1976), os números racionais não podem ser interpretados na forma fracionária, portanto são frações que podem ser comparadas, somadas, subtraídas, multiplicadas e divididas; são frações decimais que formam uma extensão natural dos números naturais; são classes de equivalência de frações; são números da forma $\mathrm{a} / \mathrm{b}$, concebendo-se $\mathrm{a}$ e $\mathrm{b}$ como números inteiros $\mathrm{e} b \neq 0$; são operadores multiplicativos; são elementos de um campo quociente ordenado e infinito (há números da forma $x=a / b$, onde $x$ satisfaz a equação $b x=a$ ); são medidas ou pontos sobre a reta numérica. Para esse autor, os números racionais na forma fracionária comportam os significados de relação parte-todo; quociente; medida; razão; operador.

Para Nunes et al (2003), conferir a fração comporta os significados de número, relação parte-todo, quociente, medida e operador multiplicativo. Como número, expressa uma posição na reta numérica, cuja notação compreende $a / b, \operatorname{com}(a \in Z, b \in Z, \operatorname{com} b \neq 0)$. Assim, é possível diferenciar quantidades $(>,<\mathrm{e}=)$, ou ainda, efetuar representação decimal. A relação partetodo comporta a ideia de partição de um todo em partes iguais (divisão), em que cada parte pode ser representada como 1/n. Como quociente, a fração indica uma divisão e seu resultado, o que denota uma relação entre duas variáveis (representadas pelas quantidades do numerador e do denominador). Como medida, elas podem se referir a quantidades intensivas, as quais se baseiam na relação entre duas quantidades diferentes - suco de limão e água que resulta na limonada -, assim como na probabilidade de um evento acontecer, caso da relação em que o valor do todo não influencia a quantidade intensiva. Como operador multiplicativo, elas podem ser concebidas como o valor escalar aplicado a uma quantidade.

\subsection{CaRacterísticas das QuantidadeS}

Segundo Nunes et al (2005), as quantidades contínuas, discretas, intensivas, extensivas, afetam o processo de compreensão conceitual da fração. As quantidades contínuas não podem ser divididas infinitamente sem perderem suas características (caso das medidas unidimensionais); as quantidades discretas referem-se a um conjunto de objetos idênticos, 
representando um único todo, cujo quociente deve resultar em unidades inteiras (quantidade de pessoas, por exemplo). Aqui se comparam duas quantidades de mesma natureza. "Quando a medida de uma quantidade baseia-se na comparação de duas quantidades da mesma natureza e na lógica parte-todo, dizemos que a medida se refere a uma quantidade extensiva" (NUNES et al, 2005, p. 123). Ainda segundo as autoras, nas quantidades intensivas estabelecem-se relações entre duas quantidades de natureza diferentes, em que a quantidade é medida pela relação entre duas variáveis distintas, resultando numa terceira. A comparação entre as quantidades de naturezas distintas pode ser escrita na forma de razão ou fração.

Podemos distinguir dois tipos de quantidades intensivas. Em algumas delas, as duas unidades diferentes estão combinadas, formando um todo. Por exemplo, quando misturamos suco concentrado e água, estamos formando um todo. Nesse caso, podemos escrever a concentração de suco de duas maneiras: 2 copos de suco concentrado para cada copo de água; ou $2 / 3$ de suco concentrado e $1 / 3$ de água. A primeira concentração é expressa na forma de uma razão; a segunda é expressa em forma de uma fração. Observe que a razão é 2 para 1; a fração é expressa na mesma relação, porém usando $2 / 3$ e $1 / 3$ (NUNES et al, 2005, p. 152).

De acordo com Carvalho (2017), nos livros didáticos é bastante usual o significado parte-todo, embora em menor incidência seja possível encontrar o operador multiplicativo. Pouco se encontra o significado de número, quociente e medida. Ademais, pouca atenção é dada em relação à natureza das quantidades.

\section{UMA ANÁLISE EM QUESTÕES DE FRAÇÃO DO SAETO}

Ao efetuarmos as análises, apresentamos cada uma das questões que envolvem fração, tanto do $9^{\circ}$ ano do Ensino Fundamental como do $3^{\circ}$ ano do Ensino Médio. Ao apresentar cada questão, indicamos seus respectivos números de acordo com o que consta na prova. $\mathrm{Na}$ sequência, efetuamos as análises, considerando o referencial teórico dos registros de representação semiótica, significados de fração e as características das quantidades. Inicialmente, cabe destacar que os enunciados das questões foram apresentados em linguagem alfabética, fazendo uso de números para indicar as quantidades.

\subsection{QUESTÕES DO 9 ANO DO ENSINO FUNDAMENTAL}

Quadro 1 - Questão do $9^{\circ}$ ano do Ensino Fundamental

03 - (SALTO-2011) Numa empresa há 270 funcionários. Dentre eles, 30\% são fumantes. Qual o número de funcionários que não são fumantes?
(A) 81
(B) 125
(C) 189
(D) 300

Fonte: Caderno de Prova (SALTO, 2011). 
O enunciado indica a quantidade de funcionários de uma empresa e informa, em registro numérico percentual (30\%), que uma parte são fumantes e a incógnita reside na quantidade de não fumantes.

$\mathrm{O}$ fato de as quantidades referirem-se a pessoas, caracteriza-se como quantidade discreta e, ao se comparar as partes de fumantes (30\%) com os de não fumantes (70\%), tem-se uma quantidade discreta e extensiva (NUNES et al, 2005).

O modo como o enunciado foi apresentado conduz o estudante a estabelecer a relação entre a(s) parte(s) (30\% ou 70\%) e o todo (270); nos termos de Nunes et al (2003), a relação parte-todo. Os estudantes podem também entender a questão como um operador multiplicativo; nos termos de Nunes et al (2003), ou seja, 30\% $=30 / 100=0,3$ ou $70 \%=70 / 100$ =0,7. Também é possível operar aritmeticamente.

Em ralação a parte-todo, os estudantes podem considerar os $30 \%$ de fumantes como uma fração (30/100) ou mesmo 3 de cada $10=3 / 10$. Nesse caso, tem-se: 30 de um 100; 30 de outro 100; e 7 vezes 3 de cada 10, o que resultaria em $30+30+(7 \times 3)=60+21=81$ fumantes. Como se pede a quantidade de não fumantes, há que se subtrair do total de funcionários; assim, $270-81=189$ não fumantes. Outra possibilidade é trabalhar com a quantidade relativa aos não fumantes (70\%), o que corresponde a 70/100 (fração) ou 70 de cada 100 e/ou ainda, 7 de cada 10 (7/10). Nesse caso, tem-se: 70 de um 100; 70 de outro 100; e 7 vezes 7 de cada 10 , o que resultaria $70+70+(7 \times 7)=140+49=189$ não fumantes.

Ao passar do registro percentual para fracionário, tem-se a conversão de que trata Duval (1993); assim, 30\% = 30/100. Na passagem de 30/100 para 3/10 (30/100 =3/10), tem-se tratamento, nos termos de Duval (1993). Ao se tratar de fração, temos a equivalência $30 / 100=3 / 10$. Do mesmo modo, pode-se verificar o percentual dos não fumantes $(70 \%=$ $70 / 100$ e $70 / 100=7 / 10)$.

$\mathrm{Na}$ perspectiva do operador multiplicativo, tem-se $30 \%=3 / 100=0,3$ de 270 (fumantes), o que significa $270-(0,3 \times 270)=270-81=189$; ou ainda, $70 \%=70 / 100=0,7$ de 270 (não fumantes), isto é $(0,7$ x 270) = 189. No campo da fração, 30\% de 270 significa 30/100. $270=8100 / 100=81$ fumantes, daí, $270-81=189$, ou ainda, 70/100. $270=18900 / 100$ $=189$.

Quadro 2 - Questão do $9^{\circ}$ ano do Ensino Fundamental 09 - (SALTO-2011) No aniversário de 40 anos de uma cidade, houve uma corrida comemorativa de 36 quilômetros. Ao longo do caminho há postos que fornecem água aos atletas. Um corredor que sai do ponto de partida encontra o primeiro posto a $1 / 4$ desse caminho. O segundo posto está a 1/3 do caminho em relação ao ponto de partida. Qual a distância do ponto de partida até o posto 2? 
(A) $6 \mathrm{~km}$

(B) $9 \mathrm{~km}$

(C) $12 \mathrm{~km}$

(D) $18 \mathrm{~km}$

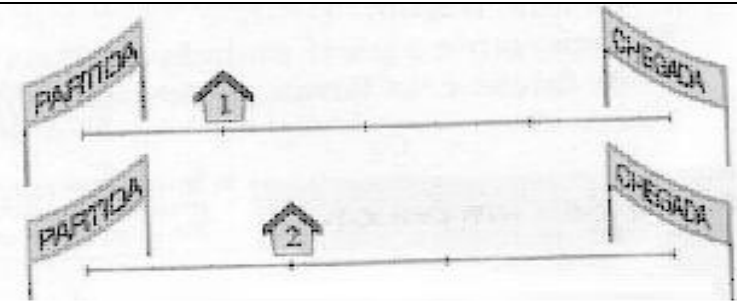

Fonte: Caderno de Prova (SALTO, 2011).

Mesmo que o problema mencione que a corrida seja uma atividade em comemoração ao aniversário de uma cidade, comumente esse tipo de situação é apresentado para fins didáticos. O enunciado informa a distância a ser percorrida $(36 \mathrm{~km})$ e dá destaque a dois pontos do trajeto (1/4 e 1/3), mas a incógnita reside na distância percorrida até o ponto 2 , indicado como 1/3. Está caracterizada uma quantidade contínua (NUNES et al, 2005), numa relação parte-todo (NUNES et al, 2003), e o registro do enunciado foi apresentado em linguagem mista, alfabética e numérica (DUVAL, 1993), com destaque no numérico fracionário.

Observa-se, no entanto, o tempo de emancipação do município (40 anos), assim como a distância entre o ponto de partida e ponto $1 / 4$, elementos que não entram em cena na pergunta do problema, mas que podem se configurar como distrações para os estudantes.

Para resolver o problema e responder ao que foi perguntado, basta entender que se trata de $1 / 3$ de $36 \mathrm{~km}$, portanto $36: 3=12 \mathrm{~km}$. Os estudantes também podem lançar mão da equivalência de fração e chegar ao mesmo resultado $(1 / 3=2 / 6=3 / 9=\ldots=12 / 36=\ldots)$, ou ainda utilizar o operador função, o qual faz passar 3 para 36, que é o mesmo que faz passar 1 para 12; ou ainda ver como uma proporção, em que fazendo uso da regra de três também se chega ao resultado.

Quadro 3 - Questão do $9^{\circ}$ ano do Ensino Fundamental

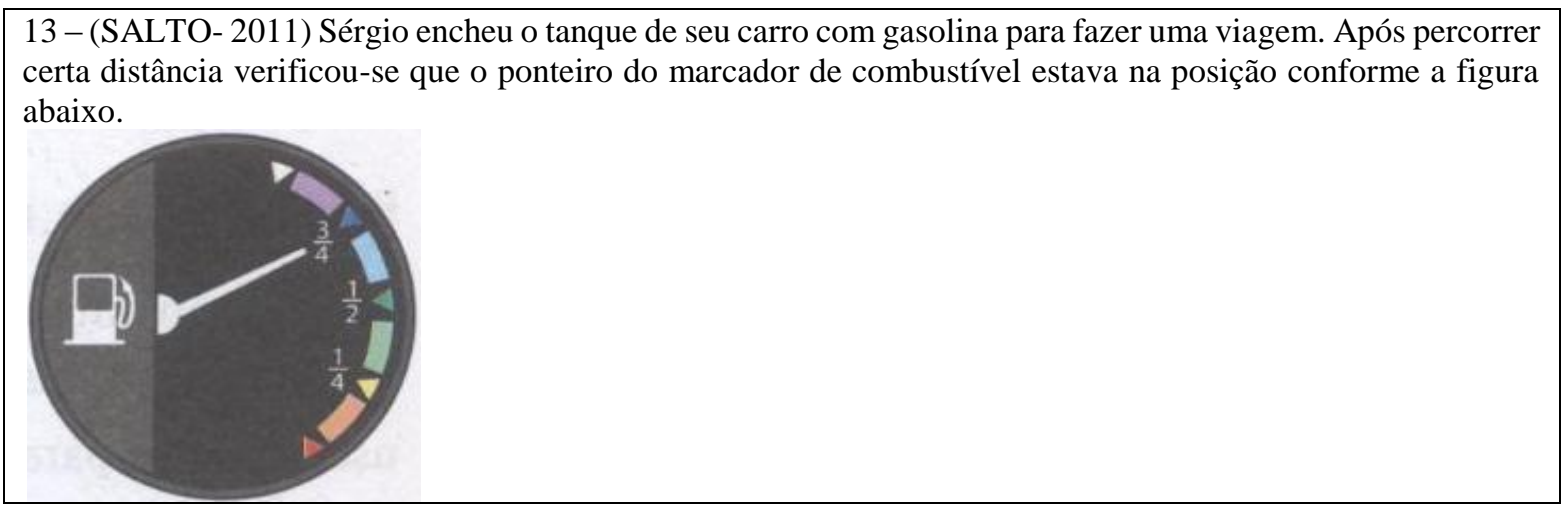


O percentual de combustível restante no tanque é:
(A) $15 \%$
(B) $25 \%$
(C) $34 \%$
(D) $75 \%$

Fonte: Caderno de Prova (SALTO, 2011).

Além da parte introdutória do enunciado em linguagem alfabética, há uma imagem cujo ponteiro do marcador indica a quantidade de combustível no tanque (1/4), sem indicar a quantidade de combustível (que o tanque comporta, ou que foi gasta, ou que ainda resta no tanque). As alternativas de resposta foram apresentadas em percentual. Temos aqui uma situação cujos registros de representação semiótica (DUVAL, 1993) constam de linguagem mista: alfabética, figural, numérica fracionária e percentual. O problema remete também a uma relação parte-todo, com quantidade contínua.

Para resolver o problema, basta que os estudantes reconheçam que 3/4 = corresponde a $75 \%$, o que, segundo Vizolli (2006), pode ser visto com frequência ao se tratar de Educação de Jovens e Adultos. Nos termos de Duval (1993), os estudantes necessitam de uma conversão do registro de representação semiótica numérico fracionário para numérico percentual, podendo perpassar pelo registro numérico decimal; assim, $3 / 4=0,75=75 \%$.

Quadro 4 - Questão do $9^{\circ}$ ano do Ensino Fundamental

15 - (SALTO - 2011) Paulo precisa trocar a metade da grama do campo de futebol que possui $110 \mathrm{~m}$ de comprimento e $85 \mathrm{~m}$ de largura.

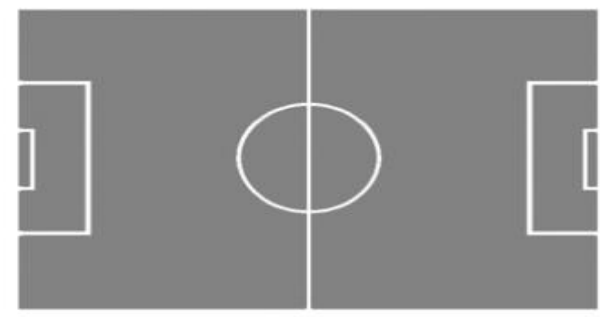

Quantos metros quadrados de grama ele precisará comprar?
(A) $18.700 \mathrm{~m}^{2}$
(B) $9.350 \mathrm{~m}^{2}$
(C) $195 \mathrm{~m}^{2}$
(D) $4.675 \mathrm{~m}^{2}$

Fonte: Caderno de Prova (SALTO, 2011).

A questão principal aqui reside no cálculo da área do campo de futebol, no entanto, suscita conhecimento de fração, vez que se refere à metade. O enunciado foi efetuado com registro de representação semiótica em linguagem alfabética e é apresentado um desenho do campo. Como a referência principal diz respeito à superfície, tem-se quantidade contínua. No tocante à fração, tem-se a uma relação parte-todo (metade da área do campo de futebol). 
Os estudantes necessitam saber que a área de um retângulo pode ser obtida pelo produto de suas dimensões; assim, $(110 \times 85)=9.350 \mathrm{~m}^{2}$. Uma vez que se trata de metade da área, temse $(9.350: 2)=4.675 \mathrm{~m}^{2}$.

Quadro 5 - Questão do $9^{\circ}$ ano do Ensino Fundamental

16 - (SALTO - 2011) A fração abaixo que é equivalente a 1/2 é:
(A) $2 / 10$
(B) $5 / 10$
(C) $7 / 10$
(D) $9 / 10$

Fonte: Caderno de Prova (SALTO, 2011)

Considerando-se o nível de escolaridade dos estudantes, a questão nos parece bastante fácil, isso porque não requer mudança de registro. Nos termos de Duval (1993), tem-se a função de tratamento. Nesse caso, basta reconhecer que se trata de equivalência. Assim, o operador função 5 faz passar 1/2 para 5/10. Para Vizolli (2006, p. 101), “a equivalência é uma qualidade de equivaler. Ela subjaz o princípio da igualdade, mas não significa igual. É aquilo que apresenta o mesmo valor, respeitando-se a proporcionalidade. [...] Assim como na comparação, a razão entre as partes se mantém" (grifo do autor).

\subsection{QUESTÕES DO $3^{\circ}$ ANO DO ENSINO MÉDIO}

Quadro 6 - Questão do $3^{\circ}$ ano do Ensino Médio O5-(SALTO-2011) O trecho da reta numérica que
vai de -1,1 a 2,5 será dividido em seis segmentos
de mesmo comprimento, que serão representados
por A, B, C, D, E e F, como mostra a figura abaixo.

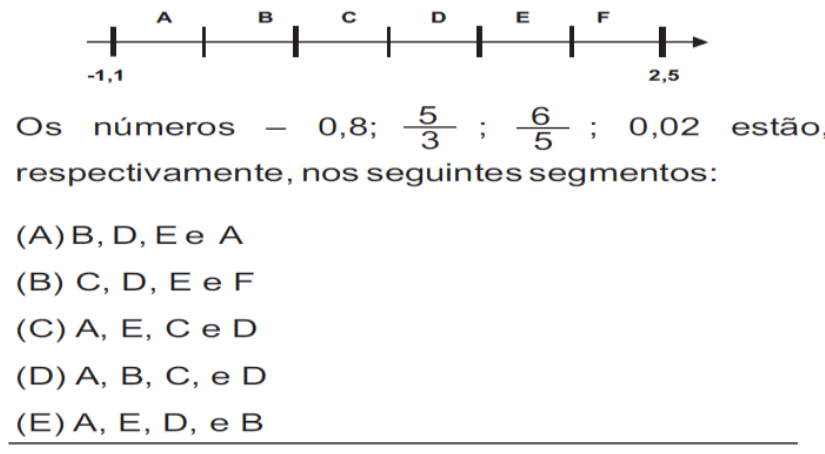

Fonte: Caderno de Prova (SALTO, 2011).

Aos estudantes do $3^{\circ}$ ano do Ensino Médio foi demandado que resolvessem a questão cujo enunciado foi apresentado em linguagem natural, com dados e informações em registros numéricos decimais e fracionários.

A questão requer a identificação da medida de cada um dos segmentos, num intervalo de segmento de reta compreendido entre $-1,1$ e 2,5. Trata-se de uma quantidade contínua 
(NUNES et al, 2005), representada sobre um segmento de reta, cujos pontos foram expressos com registros de representação semiótica numérico decimal $(-0,8$ e 0,02$)$ e fracionário $(5 / 3$ e 6/5), conforme Santana (2012). Uma vez que as alternativas se referem a medidas, há que se converter (DUVAL, 1993) 5/3 e 6/5 em decimal, assim, 5/3 =5:3=1,6666... e 6/5 =6 $6: 5=$ 1,2. Nesse caso, a fração pode ser vista como número, implicando numa divisão.

Para resolver a questão, os estudantes devem reconhecer que a medida do segmento da reta é demarcada com números do campo do conjunto dos racionais $(-1,1$ até 2,5$)$, indicando que seu início antecede o ponto de origem $(0)$, o que caracteriza o módulo de $[-1,1+0]=1,1$, quantidade a ser adicionada no módulo que vai de 0 até 2,5 . Assim, $[1,1+2,5]=3,6$. Uma vez que são 6 intervalos de mesma medida, tem-se 3,6:6=0,6 como medida de cada segmento. Assim, o segmento "A" compreende a medida de $[-1,1+0,6]=[-0,5]$, portanto $-0,5$, no qual se encontra o ponto $-0,8$; o segmento " $\mathrm{B}$ " vai de $-0,5$ até $0,1[-0,5+0,6]$, no qual se encontra o ponto 0,02 ; $C$ vai de 0,1 até 0,7 , ou seja, de $[0,1+0,6] ; \mathrm{D}=[0,7+0,6]=1,3$, no qual se encontra o ponto $6 / 5=1,2 ; \mathrm{E}=[1,3+0,6]=1,9$, onde se situa o ponto 1,666 ; e vai até $2,5[1,9+0,6]$. Logo, a sequência dos pontos é: A, E, D e B, o que corresponde à alternativa "E".

\section{TECENDO CONSIDERAÇÕES}

Reiteramos que nem todas as questões apresentam somente características de fração, mas podem ser resolvidas a partir do entendimento de fração, como é o caso da porcentagem. Isso corrobora com o que preconiza Duval (1993), quando assevera que existem diferentes registros de representação semiótica para um mesmo objeto matemático.

A maioria das questões que envolvem fração, constantes da prova do SAETO analisada, foram apresentadas em linguagem mista contemplando, sobretudo, registros de representação semiótica (DUVAL, 1993) em linguagem alfabética, numérico (fracionário, decimal e percentual). Em alguns casos, constam registros intermediários também semióticos, como reta numérica figural (medidor de combustível, campo de futebol e pista de corrida).

Para se chegar às respostas da maioria das questões apresentadas, faz-se necessário o processo de conversão, nos termos de Duval (1993), exceto na questão 16 do $9^{\circ}$ ano do Ensino Fundamental, a qual exige somente o tratamento, fazendo passar de um registro semiótico da forma de fração para outro também fracionário, o que pode ser visto como uma equivalência fracionária. 
A maioria das questões apresenta características do significado da relação parte-todo, embora os significados de número (localização na reta numérica) e de operador multiplicativo também figuram, neste caso, especialmente quando envolve quantidades.

As características da quantidade indicadas na maioria dos enunciados remetem a quantidades contínuas e extensivas. Poucas vezes encontraram-se quantidades discretas, e não figuraram quantidades contínuas e intensivas.

A literatura que versa sobre o processo de ensino e aprendizagem de fração orienta para que os professores deem a devida atenção ao uso de diferentes registros de representação semiótica, aos significados de fração, bem como em relação às características das quantidades. Partindo desse pressuposto, orientamos que tais aspectos também sejam observados por ocasião das provas do SAETO.

Desse modo, entendemos que a avaliação educacional tem intencionalidade e mantém intrínseca relação com a concepção de educação. Seja qual for o objeto de avaliação, o delineamento adotado em sua implantação, o planejamento e a divulgação dos resultados precisam se fazer presentes no projeto político educacional e social da instituição, assim como os caminhos a serem percorridos na busca incessante do processo de ensino e aprendizagem de qualidade aos estudantes.

\section{REFERÊNCIAS}

BERTONI, Nilza Eigenheer. História da SBEM Sociedade Brasileira de Educação Matemática. In: ENCONTRO NACIONAL DE EDUCAÇÃO MATEMÁTICA, 8, 2004, Recife-PE. Anais... CD-ROM. Recife: Universidade Federal de Pernambuco, 2004.

BERTONI, Nilza Eigenheer. Educação e linguagem matemática 4. Módulo V, vol. 2. Brasília: Universidade de Brasília, 2002.

BONAMINO, Alicia Maria Catalano de. Tempos de avaliação educacional: o SAEB, seus agentes, referências e tendências. Rio de Janeiro: Quartet, 2002.

CARVALHO, Euvaldo de Souza. Sequência Didática: uma proposta para o ensino do conceito de fração. 2017. 103 f. Arraias, TO: Dissertação (Mestrado Profissional em Matemática - PROFMAT). Universidade Federal do Tocantins. Arraias/TO, 2017.

DUVAL, Raymond. Registres de représentation sémiotique et fonctionnements cognitif de la pensée. In: Annales de didactique et Sciences Cognitives. Strasbourg: vol. 5, pp. 37-65. IREM-ULP, 1993.

DUVAL, Raymond. Registros de representações semióticas e funcionamento cognitivo da compreensão em matemática. In: MACHADO, S. A. D. (Org.). Aprendizagem em matemática: registros de representação semiótica. Campinas, SP: Papirus, 2003. p. 11-34. 
DUVAL, Raymond. Sémiosis et pensée humaine: registres sémiotiques et apprentissages intellectuels. Bern, Berlin, Frankfurt/M. New York, Paris, Wien: Peter Lang, editions scientifiques européennes, 1995.

DUVAL, Raymond. Semiósis e pensamento humano: registro semiótico e aprendizagens intelectuais. Fascículo I. Trad. Lênio Fernandes Levy e Marisa Rosâni Abreu da Silveira. São Paulo: Editora Livraria da Física, 2009.

FREITAS, Dirce Nei Teixeira de. Avaliação da educação básica e ação normativa federal. In: Cadernos de Pesquisa, v. 34, 2004, p. 663-689. Disponível em:

<http://www.scielo.br/pdf/cp/v34n123/a08v34123.pdf>. Acesso em: 12 abr. 2019.

GATTI, Bernadete Angelina. Avaliação de sistemas educacionais no Brasil. Sísifo. Revista de Ciências da Educação, n. 09, 2009, p. 7-18. Disponível em: 〈http://sísifo.fpce.ul.pt〉. Acesso em: 20 fev. 2019.

GIL, Antonio Carlos. Como elaborar projetos de pesquisa. 4. ed. São Paulo: Atlas, 2002.

KIEREN, Thomas; PIRIE, Susan. On the mathematical, cognitive, and instructional foundations of rational numbers. In: LESH, R. (Ed.). Number and Measurement: Paper from a research workshop. Columbos/Ohio: ERIC/MEAC, 1976. p. 101-144.

MERLINI, Vera Lucia. O conceito de fração em seus diferentes significados: um estudo diagnóstico com alunos de $5^{\mathrm{a}}$ e $6^{\mathrm{a}}$ séries do ensino fundamental. 2005. 238 f. São Paulo: Dissertação (Mestrado em Educação Matemática). Pontifícia Universidade Católica. São Paulo, 2005.

NUNES, Terezinha; CAMPOS, Tânia Maria Mendonça; MAGINA, Sandra; BRYANT, Peter. Educação matemática 1: números e operações numéricas. São Paulo: Cortez, 2005.

NUNES, Terezinha; BRYANT, Peter; PRETZLIK, U.; HURRY, J. The effect of situations on children's understanding of fractions. In: BRITISH SOCIETY FOR RESEARCH ON THE LEARNING OF MATHEMATICS. Anais... Oxford, jun. 2003.

NUNES, Terezinha; BRYANT, Peter. Crianças Fazendo Matemática. Porto Alegre/RS: Artes Médicas, 1997.

SALTO - SISTEMA DE AVALIAÇÃO DA EDUCAÇÃO DO ESTADO DO TOCANTINS. Caderno do Aluno: $9^{\circ}$ ano ( $8^{\mathrm{a}}$ série $)$ do Ensino Fundamental. Tocantins, 2011.

SALTO - SISTEMA DE AVALIAÇÃO DA EDUCAÇÃO DO ESTADO DO TOCANTINS. Caderno do Aluno. $3^{\text {a }}$ Série do Ensino Médio. Tocantins, 2011.

SANTANA, Larissa Elfísia de Lima; LIMA, Luíza Helena Martins; SILVA, Silvana Holanda; OLIVEIRA, Bárbara Pimentel. Frações e seus diferentes registros de representação semiótica: uma análise da percepção de futuros pedagogos. In: ENCONTRO NACIONAL DE EDUCAÇÃO MATEMÁTICA: EDUCAÇÃO MATEMÁTICA: RETROSPECTIVAS E PERSPECTIVAS, 11, 2013, Curitiba. Anais... Curitiba: SBEM, 2013. 
SANTANA, Larissa Elfísia de Lima. Os saberes conceituais de pedagogos em formação inicial, acerca de Fração. 2012. 182 f. Fortaleza: Dissertação (Mestrado Acadêmico em Educação). Universidade Estadual do Ceará. Fortaleza, 2012.

SOUSA, Sandra Zákia. Concepções de Qualidade da Educação Básica Forjadas por meio de Avaliações em Larga Escala. Avaliação, Campinas, v. 19, n. 2, jul. 2014, p. 407-420.

SOUSA, Sandra Zákia. Avaliação externa em larga escala no âmbito do estado brasileiro: interface de experiências estaduais e municipais de avaliação da educação básica com iniciativas do governo federal. In: BAUER, Adriana; GATTI, Bernadete Angelina. (Orgs.). Vinte e cinco anos de avaliação de sistemas educacionais no Brasil: implicações nas redes de ensino, no currículo e na formação de professores. Florianópolis/SC: Insular, 2013. p. 6185. Disponível em: <http://www.producao.usp.br/handle/BDPI/44535>. Acesso em: 28 nov. 2018.

TOCANTINS. Lei no 2.977, de 08 de julho de 2015. Publicada no Diário Oficial no 4.411. Aprova o Plano Estadual de Educação do Tocantins - PEE/TO (2015-2025). Disponível em: <https://central3.to.gov.br/arquivo/412370/>. Acesso em: 21 fev. 2019.

VIZOLLI, Idemar. Registros de alunos e professores de educação de jovens e adultos na solução de problemas de proporção-porcentagem. 2006. 245f. + 188 anexos (CD). Curitiba: Tese (Doutorado em Educação). Universidade Federal do Paraná. Curitiba/PR, 2006.

VIZOLLI, Idemar. Registros de representação semiótica no estudo de porcentagem. 2001. 245 f. Florianópolis: Dissertação (Mestrado em Educação). Universidade Federal de Santa Catarina. Florianópolis/SC, 2001.

Recebido em:15 de março de 2019.

Aprovado em: 14 de maio de 2019. 